\title{
CHEMORECEPTION OF THE LATERAL-LINE ORGAN OF AN AQUATIC AMPHIBIAN, XENOPUS LAEVIS
}

\author{
Norihiko ONODA* and Yasuji KATSUKI** \\ *Department of Physiology, School of Medicine, Tokyo Medical and Dental University, \\ Tokyo 113, Japan \\ **Department of Physiology, School of Dentistry, Tsurumi Women's University, \\ Tsurumi-ku, Yokohama 230, Japan
}

Summary The lateral-line organ of Xenopus laevis was studied by recording responses from its afferent nerve fiber. The firing rate was registered with the aid of an electronic rate meter.

1. The firing rate was remarkably increased by stimulation with $\mathrm{KCl}$ and $\mathrm{NH}_{4} \mathrm{Cl}$.

2. Sodium salts (except for Na-glutamate) suppressed both the spontaneous activity and responses to other cations. Na-glutamate did not show the suppressive effect at all.

3. Salts of divalent cations, $\mathrm{CaCl}_{2}$ and $\mathrm{MgCl}_{2}$, increased the firing rate, in contrast to the results obtained with fish, where they suppressed the responses to monovalent cations.

4. The discharge pattern from all the afferent fibers examined was quite uniform, so that the fibers could not be separated by response patterns into different groups.

5. Neither tetrodotoxin nor $\mathrm{Mn}^{++}$suppressed the responses to solutions of salts, including those of $\mathrm{Ca}^{++}$.

6. Sucrose and quinine produced no remarkable effects, in contrast to the effects produced on the gustatory organs.

7. Dihydrostreptomycin sulfate (SM) suppressed both mechano- and chemoreception.

8. Along with serving as a mechanoreceptor, the lateral-line organ of Xenopus probably functions as an external chemosensory organ in detecting ions in the environment.

Based on morphological and physiological studies, the lateral-line organ of aquatic vertebrates has been believed to be a mechanoreceptor (KATSUKI et al.,

Received for publication November 8, 1971

小野田法彦, 勝木保次 
1951; Jielof et al., 1952; Murray, 1955; GöRner, 1961; DijkgraAF, 1963; Flock, 1966; HARris and Milne, 1966). However, Katsuki et al. (1969) found that some of the lateral-line organs in the shark have dual functions, mechanoreception and chemoreception. Further studies with other kinds of fish showed that the pit organ, in which the presence of the cupula has not been morphologically confirmed, has dual functions, while the canal organ, which possesses a cupula, is concerned only with mechanoreception (KATSUKI and HASHIMOTO, 1969; KATSUKi et al., 1970; KATSUKI et al., 1971).

In the present paper, we have examined the chemical sensitivity of the lateralline organ of a South African clawed toad (Xenopus laevis). It will be shown that this organ does have the function of chemoreception, in spite of the existence of the typical cupula. A preliminary note has already appeared (ONODA et al., 1970).

\section{MATERIALS AND METHODS}

The material used was 20 clawed toads with a body length of $5-7 \mathrm{~cm}$. The animal was anesthetized by injecting a solution of $3 \%$ urethane and was fixed on a board in prone position, as shown in Fig. 1. When the dorsal skin of the animal was cut 5-10 $\mathrm{mm}$, from rostral to caudal near the forelimb, the two nerve trunks innervating the lateral-line organs of the upper and middle lateral row were visible (Murray, 1955; Harris and Milne, 1966). After one of the nerve trunks was exposed and cut, the central end of its peripheral part was placed under a binocular microscope and separated with a pair of sharpened tweezers into many thin bundles containing a few fibers each. A diagram of methods for recording neural responses is shown in Fig. 1. The bundle was suspended by a chlorinated silver wire electrode $100 \mu$ in diameter and the potentials were recorded against

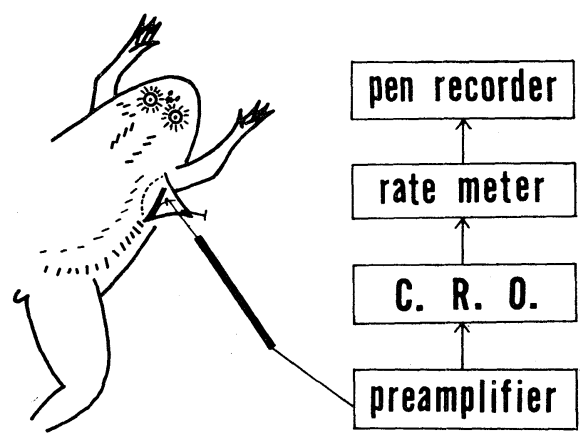

Fig. 1. Experimental arrangement for recording impulses from the lateral-line nerve fiber of an anesthetized Xenopus. The recorded signals were processed as shown by the block diagram. C.R.O.: cathode ray oscilloscope. 
the indifferent $\mathrm{Ag}-\mathrm{AgCl}$ plate electrode which was placed under the ventral side of Xenopus body. The signals were amplified with a high gain preamplifier (Tektronix 122) through a conventional cathode follower head stage (Nihon Kohden $\mathrm{MZ} 4$ ) and displayed on an oscilloscope screen (Tektronix 565). The number of nerve impulses per unit time interval $(500 \mathrm{msec}$ or $1,000 \mathrm{msec}$ ) was also recorded through an electronic rate meter.

In this experiment, various kinds of ionic solutions were used as test stimuli: $\mathrm{KCl}, \mathrm{NH}_{4} \mathrm{Cl}, \mathrm{NaCl}, \mathrm{NaNO}_{3}, \mathrm{NaCH}_{3} \mathrm{SO}_{4}, \mathrm{Na}$-glutamate, $\mathrm{CaCl}_{2}, \mathrm{MgCl}_{2}$ and other chemicals. The test solutions were prepared in a reciprocal of two power series by a repeating two-fold dilution method. Solutions were applied with a syringe to a small restricted area innervated by the nerve fiber concerned. In most cases, the period of application of an ionic solution was about 1 min. After that, the body surface was rinsed well with distilled water. Special attention was given to make sure that spontaneous discharges returned to the original steady rate before the next test solution was applied to the same area.

\section{RESULTS}

Spontaneous discharges of the lateral-line nerve fiber remained at a fairly constant rate for a considerable time. We found the location of the receptive field by gently touching various areas of the skin with a small, soft-haired brush.

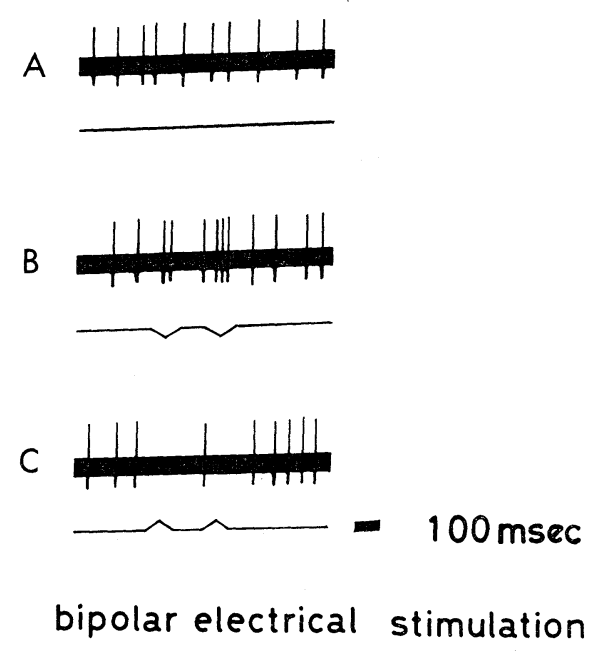

Fig. 2. Spontaneous discharges of a single lateral-line nerve fiber and the effect of polarizing current applied to the receptive field. The current was applied through a pair of electrodes on the skin. Upper traces in $\mathrm{A}, \mathrm{B}$, and $\mathrm{C}$ show the discharge pattern. The lower traces show the polarizing current. A: No polarizing current. B and C: with polarizing current. The direction of the current in $\mathrm{C}$ is the reverse of that in $\mathrm{B}$. Note the change in discharge frequency during polarization. 
At the receptive field, the touch caused a typical burst-like discharge. Further confirmation of the receptive field was made by applying a polarizing current through a pair of electrodes. As shown in Fig. 2, the current caused an increase or a decrease of the firing rate, depending on its direction. When a salt solution was applied to the receptive field, the rate of discharge of the nerve fiber increased rapidly after a few seconds of latency, reaching a steady state within $10 \mathrm{sec}$. With a solution of lower concentration, the response remained in a steady state for as long as $20 \mathrm{~min}$. When the skin was washed with distilled water, the increased discharge rate returned quickly to the level of spontaneous firing. Therefore, the response was reversible. Examples of the discharge pattern are shown in Figs. $3,5,6,8$, and 9 .
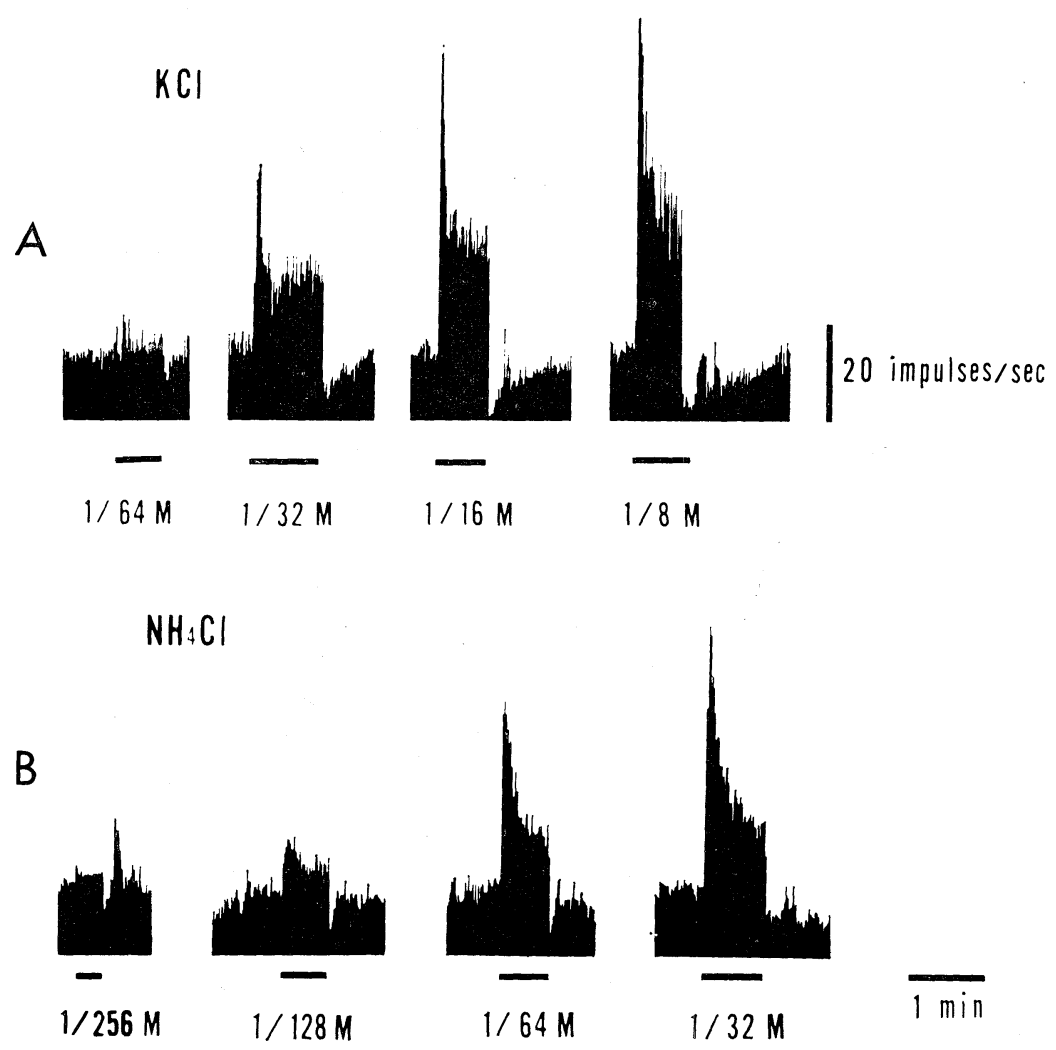

Fig. 3. Changes in the rate of firing of a single fiber produced by solutions of $\mathrm{KCl}$ and $\mathrm{NH}_{4} \mathrm{Cl}$. The records were drawn by a pen recorder (Toa EPR-3T) which displays the output of an electronic rate meter (see METHODS). The ordinate gives the number of impulses per second. The abscissa gives time. The horizontal bar under each record gives the period of application of the test solution to the receptive field. After application of the test solution, the skin was rinsed with distilled water. 


\section{Salts with monovalent cations}

A. $\mathrm{KCl}, \mathrm{NH}_{4} \mathrm{Cl}$. Figure 3 shows discharge patterns obtained when $\mathrm{KCl}$ or $\mathrm{NH}_{4} \mathrm{Cl}$ solutions of various concentrations were applied to the lateral-line organ. The threshold concentrations in this case were about $1 / 64 \mathrm{M}$ for $\mathrm{KCl}$ and $1 / 256 \mathrm{M}$ for $\mathrm{NH}_{4} \mathrm{Cl}$. With application of $1 / 32 \mathrm{M} \mathrm{KCl}$ solution, the discharge rate was increased to approximately twice that of the spontaneous level. As shown in this figure, the discharge showed an initial phasic increase for a few seconds but soon began to fall gradually to a continuous steady level. The initial phasic increase might be due partly to mechanoreception, as was described in detail elsewhere (Katsuki and Hashimoto, 1969; НаShimoto and Katsuki, 1971). With 1/4 M $\mathrm{KCl}$ solution, the nerve responses failed to remain at a steady rate and tended to decrease gradually. When the receptive field was rinsed with distilled water, the discharge rate quickly decreased to zero and gradually returned to the spontaneous level again. The relation between the concentration of $\mathrm{KCl}$ solution and the neural responses is plotted in Fig. 4 (stars). A linear relation is observed between the discharge rate and the logarithm of salt concentrations. In most receptors, the threshold concentration of $\mathrm{KCl}$ ranged from $0.02 \mathrm{M}$ to $0.05 \mathrm{M}$, in agreement with the results on freshwater fishes (HASHIMOTO and KATSUKI, 1969; KATSUKI et al., 1971).

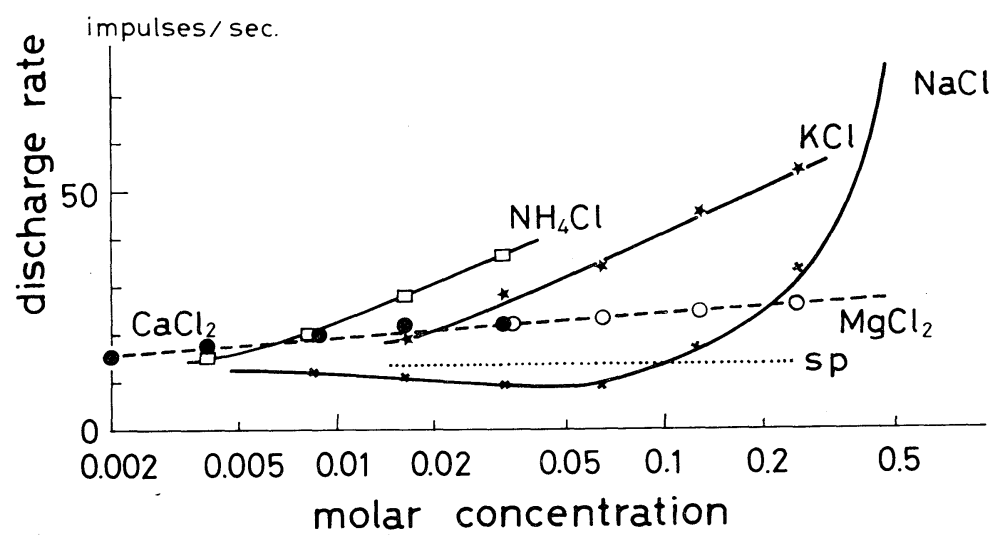

Fig. 4. Relation between the discharge rate and concentrations of salt solutions on the lateralline organ of Xenopus. All responses were obtained from the same receptor. The ordinate shows the molar concentration and the abscissa gives the number of impulses per second. The dotted line (sp) shows the rate of the spontaneous discharge. Note that the discharge rate with dilute $\mathrm{NaCl}$ solutions was lower than the spontaneous level.

As can be seen in Fig. $3 \mathrm{~A}$, the return to the spontaneous level after rinsing the receptor with distilled water became more gradual when the concentration of applied $\mathrm{K}^{+}$solution became higher. Since the application of distilled water did not cause any prominent increase in the discharge rate, the major part, at the 
least, of the increase in the discharge rate in response to application of $\mathrm{KCl}$ solutions is due to chemoreception and not to mechanoreception.

Figure $3 \mathrm{~B}$ shows the response when $\mathrm{NH}_{4} \mathrm{Cl}$ solutions were applied to the same receptor. The temporal pattern of the neural response was similar to the results with $\mathrm{KCl}$ solutions, but the threshold concentration was much lower. Since Xenopus can be classified as a predator, these results are in good agreement with the general statement that, among the various salt solutions, predatory animals are exceptionally sensitive to $\mathrm{NH}_{4} \mathrm{Cl}$ (BEIDLER et al., 1955; KATSUKI et al., 1971).

$B$. Na salts. The effects of the $\mathrm{Na}$ ion were different from those of other cations examined. As shown in the curve for $\mathrm{NaCl}$ in Fig. 4, in a lower concentration range, $\mathrm{NaCl}$ suppresses the neural response. Figrue 5 shows an example of the suppression of spontaneous discharges by a dilute $\mathrm{NaCl}$ solution. In Fig. $5 \mathrm{~A}$, the lower trace is the control with distilled water. The burst-like discharges produced at the time of water application (arrow) are probably due to mechanoreception rather than chemoreception. Solutions of $1 / 500 \mathrm{M}$ and $1 / 250 \mathrm{M}$ $\mathrm{NaCl}$ produced a slight suppression for an initial $10 \mathrm{sec}$, followed by a gradual return to the spontaneous level. The suppressive effect was, therefore, transient. With $\mathrm{Na}^{+}$concentrations between $1 / 128 \mathrm{M}$ and $1 / 32 \mathrm{M}$, the suppressive effect, though still small, persisted until the skin including the end organ was rinsed with distilled water. Strong suppressive effects appeared immediately after the application of $\mathrm{Na}^{+}$in concentrations higher than $1 / 16 \mathrm{M}$, but this effect was soon reversed and the discharge rate became higher than the spontaneous level. The time required before the discharge rate exceeded the spontaneous level differed according to the concentration of the solution applied. With application of $1 / 4 \mathrm{M} \mathrm{NaCl}$, the impulse rate increased after a suppression of only several seconds' duration. After a lapse of $1 \mathrm{~min}$, the rate became about twice the spontaneous rate. When $1 / 2 \mathrm{M} \mathrm{NaCl}$ solution was applied (not shown), the discharge showed an initial phasic increase, followed by a gradual decrease leading to a rate below the spontaneous level. The average rate of discharge during the initial $30 \mathrm{sec}$ is plotted against the $\mathrm{NaCl}$ concentrations in Fig. $5 \mathrm{~B}$. The curve is not monotonic. The discharge rate decreases gradually with increasing $\mathrm{NaCl}$ concentration in the range from $0.001 \mathrm{M}$ to $0.05 \mathrm{M}$, but in the higher concentration range it increases rapidly. The suppressive effect is strongest at concentrations between $0.03 \mathrm{M}$ and $0.07 \mathrm{M}$.

Other $\mathrm{Na}$ salts $\left(\mathrm{NaNO}_{3}, \mathrm{Na}\right.$-methylsulfate and Na-glutamate) were also tested. The neural responses to these chemicals are shown in Fig. 6. Both $\mathrm{NaNO}_{3}$ (A) and $\mathrm{NaCH}_{3} \mathrm{SO}_{4}$ (B) showed a suppressive effect similar to that observed with $\mathrm{NaCl}$ at concentrations lower than $1 / 8 \mathrm{M}$. As indicated in Fig. 7, three $\mathrm{Na}$ salts, i.e., $\mathrm{NaCl}$ (filled circles), $\mathrm{NaNO}_{3}$ (crosses), and $\mathrm{NaCH}_{3} \mathrm{SO}_{4}$ (open circles), showed a similar tendency. But Na-glutamate (stars) differs from the other three salts in that this salt does not produce any suppressive effect. As judged from the temporal patterns shown in Fig. 6C and from the concentration-effect curve shown in Fig. 7 (stars), the effects of Na-glutamate were similar to $\mathrm{KCl}$ and $\mathrm{NH}_{4} \mathrm{Cl}$ (Fig. 4). 

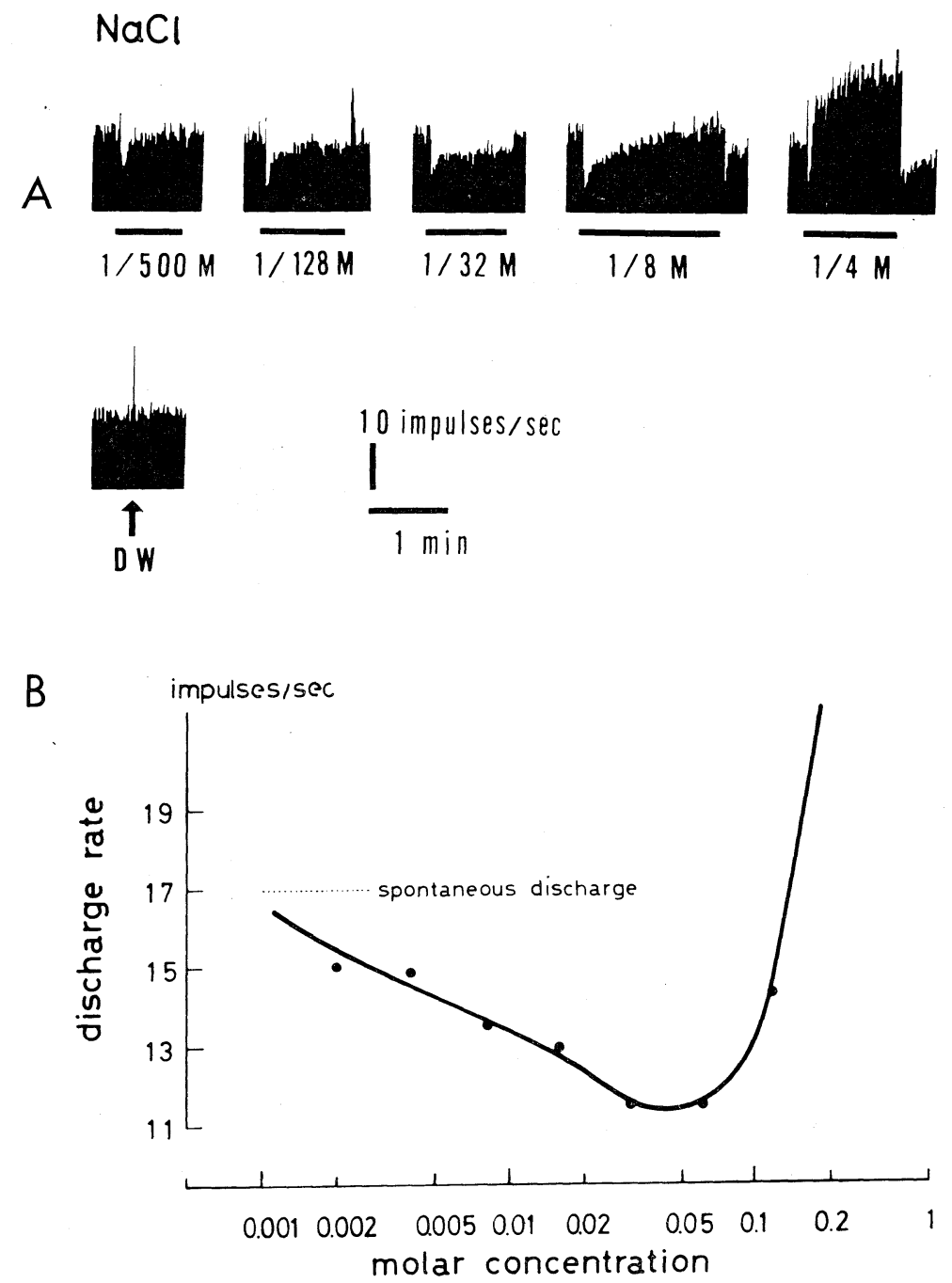

Fig. 5. Suppressive effects of $\mathrm{NaCl}$ solution. A: Rate meter records. Upper records show responses to $\mathrm{NaCl}$ application. The horizontal bar under each record shows the period of application of the test solution. The lower record shows the response to distilled water applied at the time indicated by an arrow. A burst of discharges appeared but there was no tonic increase or decrease in the rate. The experiment shown in Fig. $5 \mathrm{~A}$ is plotted in Fig. 4 (crosses) and Fig. 7 (filled circles). B: Rate of impulse discharge per second, averaged for the initial $30 \mathrm{sec}$ after application of $\mathrm{NaCl}$ solutions. The horizontal dotted line shows the spontaneous discharge level. Note that this curve is not monotonic. 

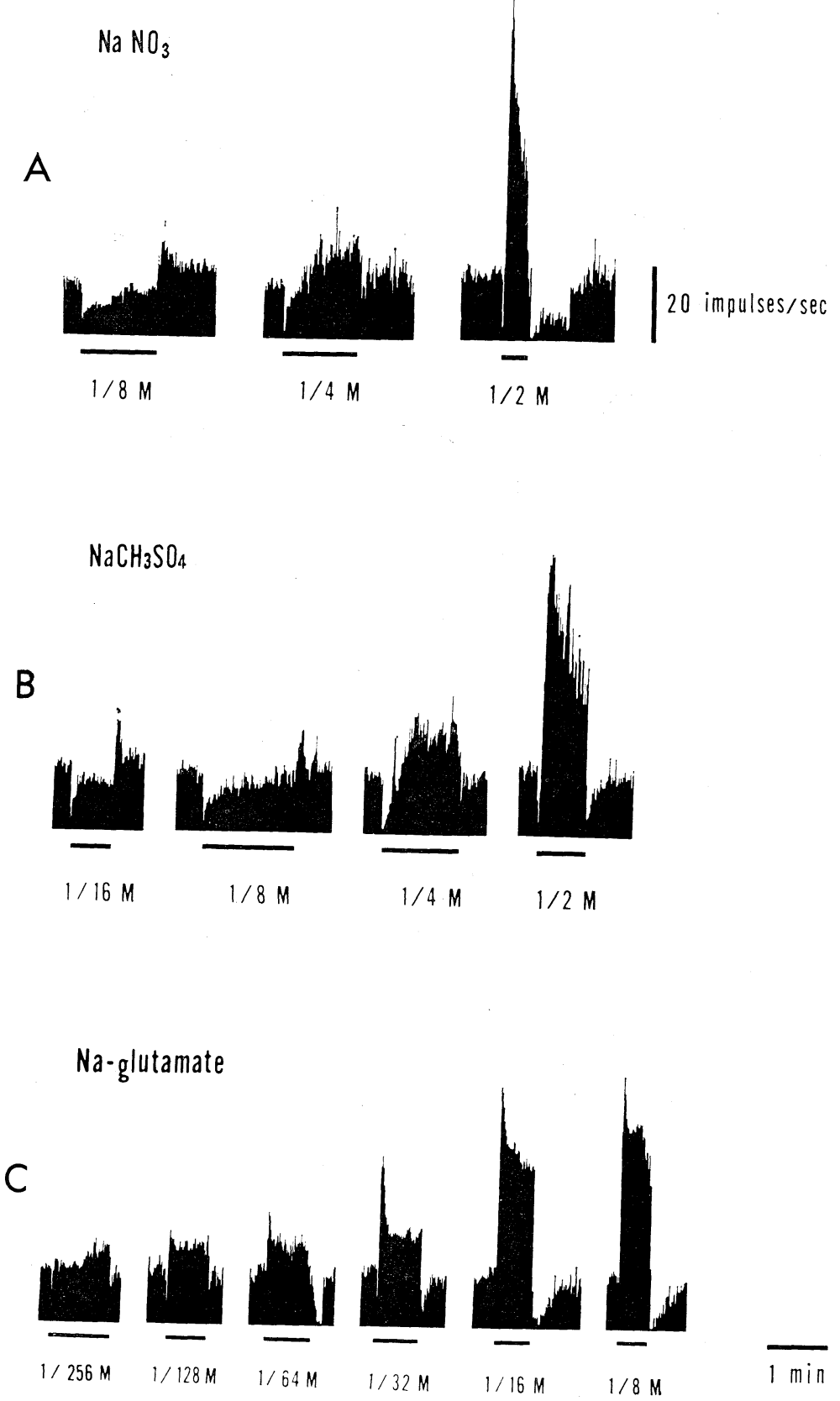

Fig. 6. Effects of three $\mathrm{Na}$ salts on the rate of afferent discharges. $\mathrm{NaNO}_{3}$ and $\mathrm{NaCH}_{3} \mathrm{SO}_{4}$ showed suppressive effects but Na-glutamate did not. Rate meter records. 


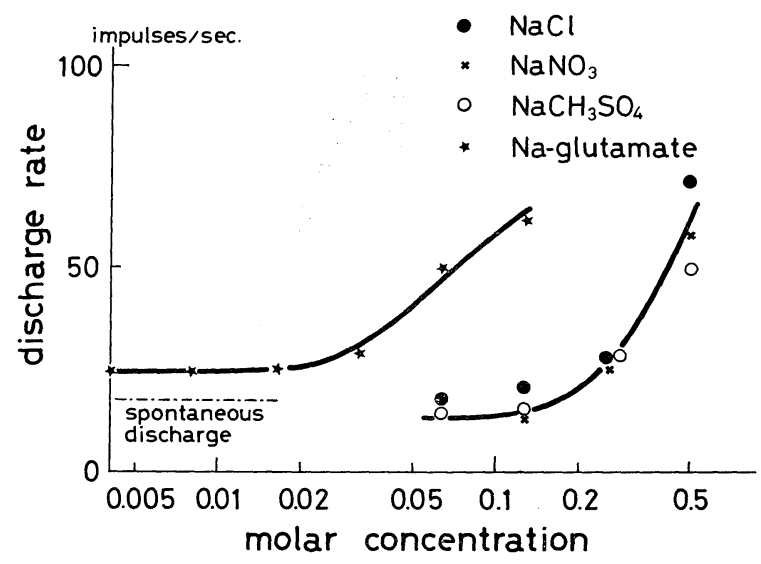

Fig. 7. Relations between molar concentrations of $\mathrm{Na}$ salts and the discharge rate. The same data as in Fig. 6. Except for Na-glutamate, Na salts showed similar tendencies.

In spite of the exceptional stimulating effect demonstrated by its glutamate salt, it seems probable that suppressive effects are elicited by the $\mathrm{Na}$ ion.

The interaction of $\mathrm{Na}^{+}$with other cations was also studied. The results are shown in Fig. 8. The records in Fig. 8 A demonstrate the responses to three different salt solutions applied separately at a concentration of $1 / 8 \mathrm{M}$. Figure $8 \mathrm{~B}$ shows the interaction of $\mathrm{NaCl}$ with $\mathrm{KCl}$ on the same receptor. First, $1 / 8 \mathrm{M} \mathrm{KCl}$ solution (thin underline) was applied, resulting in an increased discharge rate. After about $1 \mathrm{~min}, 1 / 8 \mathrm{M} \mathrm{NaCl}$ solution (thick underline) was applied without washing off the initially applied $\mathrm{KCl}$ solution. The rate of impulse discharge then declined rapidly to zero, producing a complete suppression which lasted for a few minutes. As shown in the left record of Fig. $8 \mathrm{~A}, \mathrm{NaCl}$ applied alone did not produce such a complete suppression. When $\mathrm{KCl}$ solution (broken underline) was applied, again without rinsing, the rate of discharge increased once more and its magnitude was greater than that produced by the previous application (thin underline). Figure $8 \mathrm{C}$ illustrates that $1 / 8 \mathrm{M} \mathrm{NaCl}$ suppresses responses not only to monovalent cations but also to $1 / 8 \mathrm{M} \mathrm{CaCl}_{2}$. The effect of divalent salt solution will be described in detail in Section 2.

From our results, it may be concluded that the $\mathrm{Na}$ ion suppresses both spontaneous activity and responses to other salt solutions. Such phenomena will be called the suppressive effect of or suppression by the $\mathrm{Na}$ ion. Complete suppression by the $\mathrm{Na}$ ion as shown in Fig. 8 ( $\mathrm{B}$ and $\mathrm{C}$ ) was rare. More often, some discharges were observed even during the period of suppression by the $\mathrm{Na}$ ion.

Generally, the suppression obtained from interaction of the $\mathrm{Na}$ ion with other cations was stronger than the suppression of the spontaneous discharges by $\mathrm{Na}^{+}$ alone. It was found that a $\mathrm{LiCl}$ solution produced a similar suppressive effect, but detailed studies were not performed. 

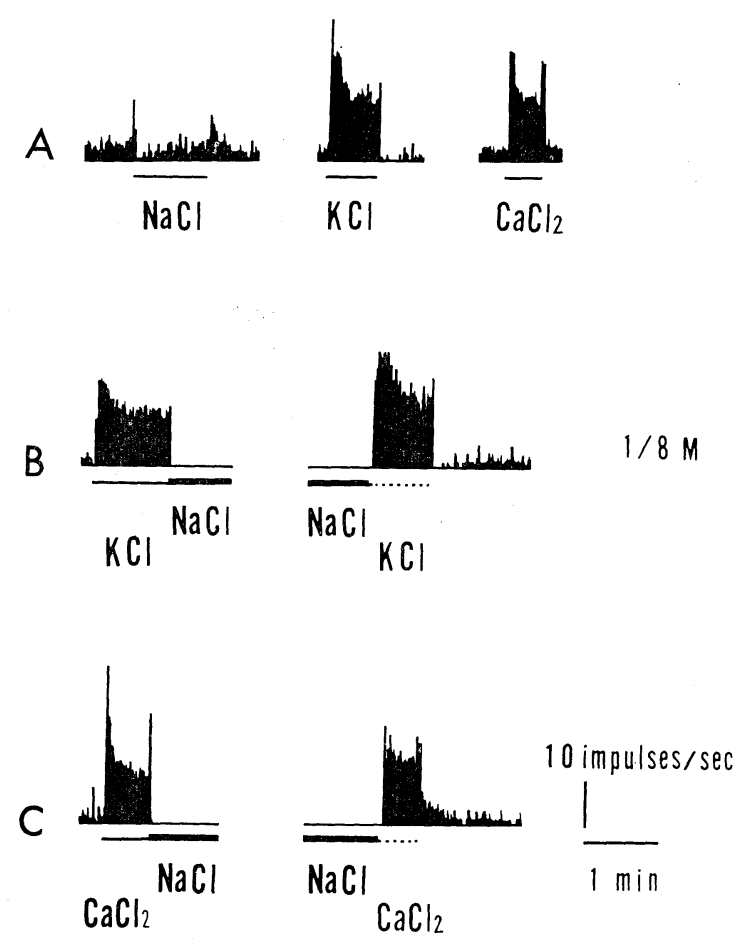

Fig. 8. Interaction of $\mathrm{NaCl}$ with other cations. $\mathrm{A}$ is the control. Solutions of single salt were used for stimulation. Concentrations are always $1 / 8 \mathrm{M}$. Thin lines under each record show the periods of application of the salt solutions. $\mathrm{NaCl}$ solution had a suppressive effect. B: The interaction of $\mathrm{NaCl}$ with $\mathrm{KCl}$. The thin line under the left record shows the period of application of $\mathrm{KCl}$ solution. After about one minute, $\mathrm{NaCl}$ solution (thick line) was applied without rinsing the receptive field with distilled water. A complete suppressive effect was produced quickly and it continued for a few minutes. The right record is a continuation of the left record and shows that $\mathrm{NaCl}$ application (thick line) maintained the complete suppression of the discharge. When $\mathrm{KCl}$ solution was applied, again without washing by distilled water (dotted line), a response reappeared which was similar to the one produced by the first application of $\mathrm{KCl}$ solution. At the end of the dotted line the skin was rinsed with distilled water. The discharge rate returned to the spontaneous level. $\mathrm{C}$ : The interaction of $\mathrm{NaCl}$ with $\mathrm{CaCl}_{2}$. The application of solutions was the same as in $\mathrm{B}$, except for the fact that $\mathrm{CaCl}_{2}$ is applied instead of $\mathrm{KCl}$.

\section{Salts with divalent cations}

Divalent cations suppressed both spontaneous activity and responses to monovalent cations in the lateral-line organ of fish. We therefore expected similar effects on the lateral-line organ of Xenopus, but the results were contrary to our expectation. Salts of divalent cations used were $\mathrm{CaCl}_{2}$ and $\mathrm{MgCl}_{2}$. Generally, the rate of discharge was increased by $\mathrm{CaCl}_{2}$ and $\mathrm{MgCl}_{2}$ to about double 
$\mathrm{CaCl}_{2}$

A

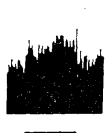

$1 / 512 M$

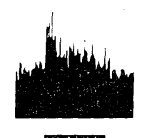

$1 / 256 \mathrm{M}$

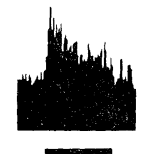

$1 / 128 M$

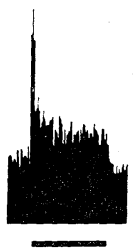

$1 / 64 M$

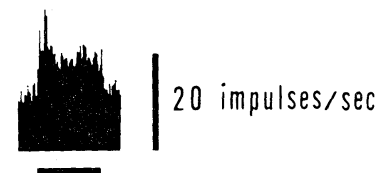

$1 / 32 M$

$$
\mathrm{MgCl}_{2}
$$

B
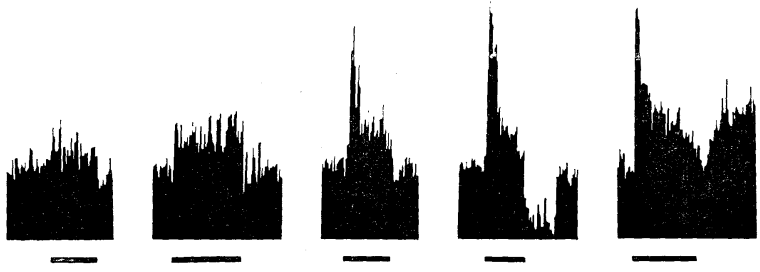

$1 / 32 M$

$1 / 8 M$

$1 / 4 M$

$1 / 2 M$

$\overline{1 \text { min }}$

Fig. 9. Responses to divalent cations. Rate meter records. A: $\mathrm{CaCl}_{2}$. B: $\mathrm{MgCl}_{2}$.

the spontaneous level. An example of the results is shown in Fig. 9. The same results have already been plotted in Fig. 4 (see the broken line). In this case, the threshold for $\mathrm{CaCl}_{2}$ was exceptionally low. However, the threshold for $\mathrm{CaCl}_{2}$ varied over a wide range among individual receptors. The threshold for $\mathrm{MgCl}_{2}$ solution was more uniform and close to the examples shown in Figs. 4 and 9.

\section{Other chemicals}

An interesting finding was that liver extract had a stimulating effect on some lateral-line organs. An example is shown in Fig. 10. On application of the test solution, the discharge rate showed a sharp dip, followed by a slow increase which lasted for about $1 \mathrm{~min}$. At the steady level, the discharge rate was about twice as great as the spontaneous activity. When the receptive field was washed with distilled water, the discharge rate returned sharply to the spontaneous level.

Such neural responses are consistent with the behavior of this animal in the aquarium. Whenever liver slices were dropped into the aquarium as food for the animal, each Xenopus became excited and swam around in the aquarium until it finally located the food. Our results suggest that the Xenopus may detect with its lateral-line organ certain chemical substances present in its food. This information from the end organs may be available in searching for food. 


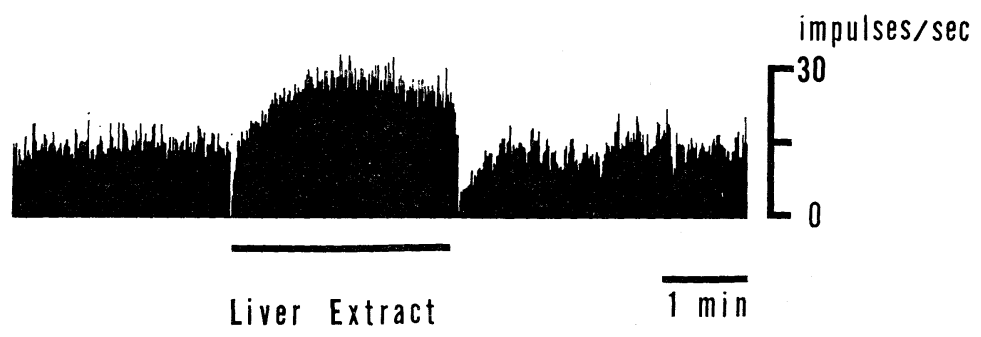

Fig. 10. Response to liver extract. Rate meter record.

Glucose, sucrose, and quinine hydrochloride were also studied, but they did not stimulate the lateral-line organ of Xenopus.

Studies were made in order to discover chemicals that suppress the response to salt solutions.

Tetrodotoxin, which suppressed the response to monovalent cations in fish, did not show in Xenopus any remarkable effect on the responses to solutions of monovalent and divalent cations even at $10^{-8}$ to $10^{-6} \mathrm{~g} / \mathrm{ml}$, which was high enough to block the nerve conduction. But at $10^{-4} \mathrm{~g} / \mathrm{ml}$, tetrodotoxin caused a reduction and irreversible disappearance of discharges in response to salt solutions. The disappearance might be attributed to the block in nerve conduction.

It is known that $\mathrm{Mn}^{++}$suppresses the Ca-spike in the frog cardiac muscle (Hagiwara and NaKaJima, 1965), in the barnacle muscle (Hagiwara and NAKAJIMA, 1966), and in the smooth muscle of the guinea pig (NoNOMURA et al., 1966). In the lateral-line organ of Xenopus, even $1 / 16 \mathrm{M} \mathrm{MnCl}_{2}$ solution did not produce any remarkable suppressive effect.

Dihydrostreptomycin sulfate (SM) suppressed both mechanoreception and chemoreception. Suppression of chemoreception by SM was not reported in a previous paper (ONODA et al., 1970) because the conditions for the suppression were not established. Detailed results will be reported in a separate paper.

\section{DISCUSSION}

a. Chemoreception at the lateral-line organ. The examples described above in RESULTS indicate that the lateral-line organ of Xenopus functions as a chemoreceptor. However, it is necessary to consider some other possible interpretations before concluding that chemoreception is performed by the lateral-line organ, which has been believed to be a typical mechanoreceptor.

The first possibility is that the receptor might be stimulated by osmotic stimuli. Since even $1.1 \mathrm{~m}$ glucose (isotonic to sea water) produced no remarkable effects, the hypertonicity of the solution can be excluded as a possible cause of stimulation of the lateral-line organ. On the other hand, hypotonicity as a cause 
of stimulation is out of the question because Xenopus lives in fresh water in the natural environment.

The second possibility is that nerve terminals innervating the lateral-line organ might be directly stimulated. This possibility is rejected since tetrodotoxin solution, which should block nerve conduction, did not affect the neural responses at all, and since $\mathrm{Mg}^{++}$solution, which is not likely to activate the nerve axon, produced some effects on the neural discharge.

The third possibility is that the lateral-line nerve might innervate other kinds of receptors that are very sensitive to the chemical stimuli applied to the body surface of Xenopus. Morphologically, however, taste bud-like structures have so far not been found on the body surface of this animal.

The fourth possibility is that the application of test solutions might produce an active movement of the end organ or the skin around the receptive field, or it might evoke a secretion of the mucus which flows over the receptive field. Xenopus might produce these reactions to avoid uncomfortable sensations. To examine this possibility, the spinal cord was destroyed completely before the experiment, but the results were still the same. Another finding contradicting this possibility is that, even with extremely dilute salt solutions, an increase in the rate of tonic impulse discharges was produced. Therefore, the possibility that the response is indirectly elicited by the movement of the end organ is quite improbable.

From the above discussion, it is reasonable to conclude that the receptor cells of the lateral-line organ of Xenopus themselves respond to chemical stimuli. It is now certain that the function of the chemoreception of the lateral-line organ of Xenopus is to provide the common chemical sense (BARDACH et al., 1967), or the external taste sense (BARDACH, 1967).

Also, in view of the findings mentioned above, we no longer have in this case any reason to believe that the lateral-line organ with a cupula is unable to respond to chemical stimuli.

b. Lack of salt specificity among end organs. All the lateral-line nerve fibers examined in the present study responded to chemical stimuli, no fiber showing any specific receptivity to different salts. Also, the order of sensitivity to different salts did not show a great difference among different fibers. Therefore, although taste fibers were divided into several groups according to their salt specificity, we could not classify lateral-line nerve fibers of Xenopus into groups (PFAFFMANN, 1941; Zotterman, 1949; Cohen et al., 1955; Kusano and Sato, 1957; Kusano, 1960; SAto and Kusano, 1960; Konishi and ZotTerman, 1961).

c. Comparison of the responses of Xenopus with those of fish. It has been reported that the lateral-line organs of fish, except for canal organs, respond to chemical stimuli (KATSUKI et al., 1969; KATSUKI and Hashimoto, 1969; KATSUKI et al., 1970; KATSUKi et al., 1971; KATSUKI and ONODA, 1971). There are two important differences between the present results and those in fish. First, in fish, the suppression elicited by $\mathrm{Na}$ ions was not found. Second, in fish, solutions of 
divalent cations suppressed responses to monovalent cations.

d. Suppression by sodium ions. Because the lateral-line organ of Xenopus is always directly exposed to fresh water, it was rinsed with distilled water in the control condition of the present experiment. If the end organ had been washed with Ringer's solution, the effects produced upon application of another test solution would have been the sum of both the suppressive effect of the $\mathrm{Na}$ ion and the stimulating effect of the other cation being tested.

Suppression by $\mathrm{Na}$ salts has already been observed in taste receptors in vertebrates: in fish (KonISHI, 1966), in frog (ZoTTERMAN, 1949; ANDERSON and ZotTERMAN, 1950; KusANo and SATO, 1957; SATO and Kusano, 1960; Yamashita, 1963), and in mammals (Pfaffmann, 1941; Cohen et al., 1955; Pfaffmann, 1955). These results have been described as the effect of water, and the afferent fibers concerned are usually called water fibers. The suppression by $\mathrm{Na}$ salts observed in the lateral-line organ of Xenopus may be understood, at least partly, as a phenomenon having the same origin as the suppression of the water response by the $\mathrm{Na}$ ion.

The suppression by dilute $\mathrm{Na}^{+}$solution is probably a general phenomenon of sensory organ responses to chemical stimuli.

e. Effectiveness of divalent cations. As shown in Fig. 9, divalent cations did not suppress responses to monovalent cations, but, on the contrary, stimulated the end organ. The tetrodotoxin (TTX) solution also suppressed neither the spontaneous activity nor responses to various kinds of salt solutions.

It is interesting to note that there seems to be a correlation between the effects of TTX and those of $\mathrm{Ca}^{++}$on the receptor membrane of the lateral-line organ. In Xenopus, the rate of impulse discharges is increased by $\mathrm{Ca}^{++}$, and TTX has no suppressive effect. In fish, the rate is not increased by $\mathrm{Ca}^{++}$, and both $\mathrm{Ca}^{++}$ and TTX have suppressive effects. One might suppose that the mechanism that generates the impulse in the lateral-line organs of Xenopus is similar to the Caspike. However, the fact that the $\mathrm{Mn}$ ion does not show any remarkable suppressive effects contradicts the above supposition.

f. The ecological role of chemoreception in Xenopus. Xenopus has no tongue, but the existence of taste buds in its oral cavity has been reported (IsHII, 1970; personal communication). Since experimental results of the study on the taste organ in Xenopus have not yet been reported, we attempted to compare the present data with the results obtained in the carp and the ordinary frog concerning the taste receptor responses to salt solutions. Taste receptors in the carp, with neural responses of types I and II as defined by KonISHI and ZOTTERMAN (1961), were less sensitive to salt solutions than the lateral-line organ of Xenopus. KonisHi (1966) later reported that $\mathrm{Na}^{+}$solutions at much more dilute concentrations than those used in the present experiment affected the taste receptors in the mouth. The threshold concentration found in the ordinary frog was not very different from our results (KuSANO, 1960). From the above discussion, it is plain that the lateral- 
line organ of Xenopus is quite an excellent ion detector.

However, the organ cannot detect the ions contained in pond water whose concentration is much lower than the lowest threshold concentration of the salts found in our studies.

Since food in the pond may temporarily produce a high enough concentration of certain ions to be located by the animal, the chemoreception of the lateral-line organ can play a role in detecting food in the watery environment, acting together with other senses, such as olfaction and vision.

This work was supported by a grant from the Ministry of Education. The authors wish to express their thanks to Professor K. Hanaoka, Institute of Endocrinology, Gumma University, and to Dr. K. Ishii, Department of Physiology, Fukushima Medical College, for supplying the experimental animals, and to Professor A. Watanabe, Professor K. Murata, and Dr. T. Hashimoto for their encouragement and invaluable advice.

\section{REFERENCES}

Andersson, B. and Zotterman, Y. (1950) The water taste in frog. Acta Physiol. Scand., 20: 95-100.

BARDACH, J. E. (1967) The chemical senses and food intake in the lower vertebrate. In The Chemical Senses and Nutrition, ed. by KARE, M. R. and MAller, O. Johns Hopkins Press, Baltimore, Md., 19-43.

BARDACH, J. E., FujIYA, M. and Holl, A. (1967) Investigation of external chemoreceptors of fishes. In Olfaction and Taste II, ed. by Hayashi, T. Pergamon Press, Oxford, 647-666.

Beidler, L. M., Fishman, I. Y. and Hardiman, C. W. (1955) Species differences in taste responses. Am. J. Physiol., 181: 235-239.

Cohen, M., Hagiwara, S. and Zotterman, Y. (1955) The response spectrum of taste fibers in the cat: A single fibre analysis. Acta Physiol. Scand., 33: 316-332.

DiJkgraAf, S. (1963) The functioning and significance of the lateral-line organs. Biol. Rev., 38: $51-105$.

FLOCK, A. (1966) Ultrastructure and function in the lateral-line organs. In Lateral Line Detectors, ed. by CAHN, P. H. Indiana Univ. Press, Bloomington, Ind., 163-197.

GorNer, P. (1961) Beitrag zum Bau und zur Arbeitsweise des Seiten-organs von Xenopus laevis. Verhandl. Deut. Zool. Ges. Saarbrücken., 193-198.

Hagiwara, S. and NaKaJima, S. (1965) Tetrodotoxin and manganese ions: Effects on action potential of the frog heart. Science, 149: 1254-1255.

Hagiwara, S. and Nakajima, S. (1966) Differences in $\mathrm{Na}$ and Ca spikes as examined by application of tetrodotoxin, procaine, and manganese ions. J. Gen. Physiol., 46: 793-805.

Harris, G. G. and Milne, D. C. (1966) Input-output characteristics of the lateral-line sense organs of Xenopus laevis. J. Acoust. Soc. Am., 40: 32-42.

Hashimoto, T. and KATSUKI, Y. (1971) Enhancement of the mechanosensitivity of hair cells of the lateral-line organs by environmental potassium ions (in preparation).

Jielof, R., SPOOR, A. and DE VRIES, H. (1952) The microphonic activity of the lateral line. J. Physiol., 116: 137-157.

Katsuki, Y., Mizuhira, V. and Yoshino, S. (1951) On the end organ of the acoustico-lateralis system of fish. Jap. J. Physiol., 2: 93-102.

KATSUKI, Y. and HASHIMOTO, T. (1969) Shark pit organs: Enhancement of mechanosensitivity by potassium ions. Science, 166: 1287-1289. 
Katsuki, Y., Yanagisawa, K., Tester, A. L. and Kendall, J. I. (1969) Shark pit organs: Response to chemicals. Science, 163: 405-407.

KATSUKI, Y. and Hashimoto, T. (1969) Chemoreception in the lateral-line system of the bony fish. Proc. Japan Acad., 45: 209-214.

KATSUKI, Y., Hashimoto, T. and YanAGisawa, K. (1970) The lateral-line organ of shark as a chemoreceptor. Adv. Biophys., 1: 1-51.

Katsuki, Y., Hashimoto, T. and Kendall, J. I. (1971) The chemoreception in the lateral-line organs of teleosts. Jap. J. Physiol., 21: 99-118.

KATSUKI, Y. and ONODA, N. (1971) The lateral-line organ of fish as a chemoreceptor (in press).

Konishi, J. and Zotrerman, Y. (1961) Taste functions in the carp. Acta Physiol. Scand., 52: $150-161$.

KoNISHI, J. (1966) Fresh water fish chemoreceptors responsive to dilute solutions of electrolytes. J. Gen. Physiol., 49: 1241-1264.

Kusano, K. and Sato, M. (1957) Properties of fungiform papillae in frog's tongue. Jap. $J$. Physiol., 7: 324-338.

KusAno, K. (1960) Analysis of the single unit activity of gustatory receptors in the frog tongue. Jap. J. Physiol., 10: 620-633.

MurraY, R. W. (1955) The lateralis organs and their innervation in Xenopus laevis. Ouart.J. Microscop. Sci., 96: 351.

Nonomura, Y., HotTa, Y. and OHASH, H. (1966) Tetrodotoxin and manganess ions: Effects on electrical activity and tension in taenia coli of guinea pig. Science, 152: 97-99.

Onoda, N., Hashimoto, T. and Katsuki, Y. (1970) Chemoreception of the lateral line organ of Xenopus laevis. Proc. Japan Acad., 46: 8, 873-877.

Pfaffmann, C. (1941) Gustatory afferent impulses. J. Cell Comp. Physiol., 17: 243-258.

Pfaffmann, C. (1955) Gustatory nerve impulses in rat, cat and rabbit. J. Neurophysiol., 18: 429.

Sato, M. and Kusano, K. (1960) Electrophysiology of gustatory receptors. In Electrical Activity of Single Cells, ed. by KatsuKI, Y. Igakushoin, Japan, 77-95.

YAMASHITA, S. (1963) Stimulating effectiveness of cations and anions on chemoreceptors in the frog tongue. Jap. J. Physiol., 13: 54-63.

ZotTERMAN, Y. (1949) The response of the frog's taste fibers to the application of pure water. Acta Physiol. Scand., 18: 181-189. 